Revista Estudios, (39), 2019.

Diciembre 2019-Mayo 2020

ISSN 1659-3316

Urbina Gaitán Chester

\title{
I Sección
}

Miradas a la trayectoria centroamericana en los dos siglos de independencia

La celebración de la independencia en Nicaragua (1866-1928)

\author{
Chester Urbina Gaitán \\ Universidad Estatal a Distancia, Costa Rica \\ chesterurbina@yahoo.com \\ https://orcid.org/0000-0001-8351-2594
}

Recibido: 25 de agosto de 2019

Aceptado: 16 de octubre de 2019

Resumen: Los contenidos políticos que se transmitieron durante los actos de celebración de la independencia en Nicaragua entre 1866 y 1895, se pueden dividir en dos períodos, el primero corresponde a los años de 1866 a 1875, donde la independencia había traído la igualdad entre los nicaragüenses, pero estos debían de moralizarse, practicar el patriotismo y el trabajo con el fin de cimentar la estabilidad política. Asimismo, se añoraba la llegada de la unión centroamericana. Entre 1877 y 1895 los discursos conmemorativos del 15 de setiembre añaden conceptos políticos que destacaban el papel "liberador" de la educación. Promovían la unidad nacional y la regeneración étnica de los nicaragüenses, pues se rescata el protagonismo del héroe nacional José Dolores Estrada y de la Campaña Nacional. También se exalta el progreso económico y la estabilidad política traída por los gobiernos conservadores. Estas peroraciones sirvieron para manifestar una visión clasista y mantener la forma de dominación imperante. Por otra parte, los textos publicados por la prensa nicaragüense sobre las celebraciones del 15 de setiembre durante el período 1903-1928, exponen las diversas influencias político-culturales que existían en esa época para tratar el tema de la identidad nacional y analizar los principales problemas por los que atravesaba Nicaragua, principalmente el de la ocupación estadounidense. Estas posturas iban del nacionalismo, al antiimperialismo y al unionismo.

Palabras clave: Formación del Estado; identidad nacional; unión centroamericana; José Dolores Estrada; valores cívicos; Iglesia católica.

\section{The celebration of independence in Nicaragua (1866-1928)}

Abstract: The political contents that were transmitted during the acts of celebrating independence in Nicaragua between 1866 and 1895, can be divided into two

La Revista Estudios es editada por la Universidad de Costa Rica y se distribuye bajo una Licencia Creative Commons Atribución-NoComercial-Compartirlgual 3.0 Costa Rica. Para más información envíe un mensaje a 
periods, the first corresponds to the years from 1866 to 1875, where independence had brought equality between Nicaraguans, but these must be moralized, practice patriotism and work in order to cement political stability. Likewise, the arrival of the Central American union was long for. Between 1877 and 1895 the commemorative speeches of September 15 added political concepts that highlighted the "liberating" role of education. They promoted national unity and the ethnic regeneration of Nicaraguans, as the role of national hero José Dolores Estrada and the National Campaign is rescued. Economic progress and political stability brought by conservative governments are also exalted. These perorations served to manifest a class vision and maintain the prevailing form of domination. On the other hand, the texts published by the Nicaraguan press on the celebrations of September 15 during the period 1903-1928, expose the various political-cultural influences that existed at that time to address the issue of national identity and analyze the main problems which Nicaragua was going through, mainly that of the American occupation. These positions went from nationalism, anti-imperialism and unionism.

Keywords: State formation; National identity; Central American Union; José Dolores Estrada; civic values; Catholic Church.

\section{Introducción}

Las naciones constituyen un fenómeno de mitificación y de toma de conciencia, surgido como el resultado de una larga elaboración histórica que puede continuar durante mucho tiempo La estructuración de una nación gira alrededor de elementos objetivos como el suelo, el grupo étnico, la lengua o la religión (Miscevic, 2000; Guibernau, 1999; Ommen, 1997; Malek, 1975, págs.127-129). Sin embargo, es necesaria que la realidad espiritual que la constituya llegue a la conciencia de sí misma. Es decir, que hasta cierto punto la interiorización a un ideal común debe ocurrir de una forma espontánea e irreflexiva, creando cierto grado de homogeneidad mental entre los integrantes de la nación (Murillo, 1972, págs.187-191; Sieyes, 1989, págs.7-14 y 143; Greenfeld, 1992, p.18). Los Estados

modernos se encargan de transmitir este sentimiento de identificación colectiva, para mantener unidos a los diferentes grupos sociales que forman la nación. Esto es así, porque la nación se puede considerar un agrupamiento político-social

\section{(c) (i) (-)}

La Revista Estudios es editada por la Universidad de Costa Rica y se distribuye bajo una Licencia Creative Commons Atribución-NoComercial-CompartirIgual 3.0 Costa Rica. Para más información envíe un mensaje a 
consistente "solo en la medida en que se refiere a cierta clase de Estado territorial moderno, el estado-nación" (Hobsbawm, 1991, p.18).

Para Eric Hobsbawm: "Las naciones no construyen estados y nacionalismos, sino que ocurre al revés" (Hobsbawm, 1991, p.18). En este sentido debe señalarse que, el festejo de las fiestas patrias en los diferentes países latinoamericanos fue teniendo cada vez más importancia en las últimas décadas del siglo XIX. Los Estados desde el sistema educativo — principalmente a través de la escuelacomienzan a fomentar el amor por la patria. Esto dio origen a los actos escolares, donde se efectuaban rituales con el objetivo de festejar los momentos históricos más relevantes de la sociedad nacional interpretados a la luz del momento. Esto lo señalan autores como Gellner (1983), Bertoni (1992), Blázquez (2000) y Mc Laren (1995).

Con respecto a la formación del Estado-nación en Nicaragua, Justin Wolfe ha señalado que, la independencia surgió en medio de ideologías colonialistas, la cual apenas culminó en el establecimiento de una identidad nacional en el país. Más bien, se abrió un vacío de poder. Españoles ricos y ladinos respondieron con luchas de poder violentas, mientras que ladinos pobres y los indios reaccionaron retirándose del control de la autoridad estatal. Por otra parte, la rivalidad entre Granada y León se intensificó por lo que no se pudo ejercer la soberanía sobre la mitad oriental del país, que se sometió al control de los británicos. En este contexto, la idea de una nación nicaragüense encontró terreno bastante inflexible para que se pudiera crear una identidad nacional a partir de los sectores populares. Podían ser parte de la nación nicaragüense pero no iban a tener ningún papel constitutivo en su formación. La mayoría de los nicaragüenses, en lugar de servir como parte del desarrollo narrativo de la nación de las élites, más bien procuraban transformar esa narrativa y sus lugares dentro de ella. La formación de una identidad nacional en Nicaragua en el siglo XIX no fue un proceso que se

\section{(c) (i) (2)}

La Revista Estudios es editada por la Universidad de Costa Rica y se distribuye bajo una Licencia Creative Commons Atribución-NoComercial-CompartirIgual 3.0 Costa Rica. Para más información envíe un mensaje a 
impuso de arriba hacia abajo, en el que las elites impusieron su proyecto de nación sobre los sectores subalternos. Lo que sucedió más bien fue que las elites y los sectores populares negociaron el significado del Estado y de la identidad nacional desde posiciones de poder desiguales. Aunque las elites utilizaron la coerción directa para crear y mantener el Estado, su utilización prolongada condujo inevitablemente a la negación de la legitimidad del Estado y al aumento de la influencia de identidades colectivas de carácter no nacional (Wolfe, 2007, p.7-9).

Para Jeffrey Gould (1995) uno de los pilares en la construcción de la nación nicaragüense es la noción de que todos sus ciudadanos son mestizos. De 1880 a 1920 la elite proyectaba imágenes de los indígenas como primitivos marginados que bloqueaban el progreso por su ignorancia y sus prácticas derrochadoras en sus propiedades comunales. Estas imágenes a la vez racionalizaban y reflejaban las políticas que llevaron a la expropiación de la tierra y a la cruda explotación del trabajo indígena, señala también Wolfe (2004).

La formación del Estado-nación en Nicaragua comenzó durante el período de los Treinta Años Conservadores (1858-1893), una vez superada la anarquía política que caracterizó al país en sus primeros treinta y siete años de vida independiente. Este grupo político manifestó su postura excluyente a nivel político en la constitución de 1858, debido a que en ella sólo eran considerados como ciudadanos los que poseían bienes y capitales. Esta Carta Magna solo otorgaba el derecho a votar a 570 personas solamente. Aunque la constitución de 1893 introdujo el sufragio universal, el país estuvo bajo el estado de emergencia durante el periodo de Zelaya y la democracia no logró asentarse como un estilo de vida para los nicaragüenses. Con el ascenso de los liberales en 1893 el país pasó de la República de la oligarquía a la dictadura de las capas acomodadas, y los

\section{(C) $(\Theta \odot$}

La Revista Estudios es editada por la Universidad de Costa Rica y se distribuye bajo una Licencia Creative Commons Atribución-NoComercial-CompartirIgual 3.0 Costa Rica. Para más información envíe un mensaje a 
trabajadores fueron sometidos a nuevas formas de explotación económica, parafraseando a Merlet (1990).

Para Michel Merlet a lo largo del siglo XIX se fue construyendo paulatinamente un sentimiento nacional, favorecido por las transformaciones económicas, y por los sucesos políticos. El impulso al cultivo del café demandó por parte del Estado intervenciones más coordinadas, una verdadera política agraria, la organización de instituciones financieras, la creación de una moneda nacional, y el mejoramiento de las vías de comunicación entre las regiones. Managua adquirió un papel clave por su posición geográfica al estar en el centro de la intersección de la red de caminos, ferrocarriles y vías fluviales que ayudaban al transporte del grano. Todo esto hizo tomar consciencia a la oligarquía de la necesidad de un Estado nacional (Merlet, 1990).

Según Frances Kinloch en Nicaragua la derrota de William Walker no se convirtió en una posibilidad de exaltar la imagen de los nicaragüenses como conjunto social. Al contrario, se reconoció la propia inferioridad étnica donde se descubrió el peso de la imagen atribuida a los pueblos del trópico por el pensamiento antropológico ilustrado [las ideas de la degradación de "la raza americana" y su incapacidad para autogobernarse], e incluso la influencia de la tesis sobre la superioridad de la raza anglosajona, esgrimida por los propagandistas del Destino Manifiesto. Empero, la elite política refirió esta inferioridad a los sectores subordinados y se reservó para sí el rol de diseminadores de la civilización europea, aunque después de casi treinta años de transitar en la anarquía la elite política comenzó a perder la esperanza en cuanto a su capacidad para instituir gobiernos estables, lo cual atribuyeron a la herencia cultural española e, incluso, a la sangre de sus ancestros (Kinloch, 2001, p.198).

\section{(c) (i) (9) (2)}

La Revista Estudios es editada por la Universidad de Costa Rica y se distribuye bajo una Licencia Creative Commons Atribución-NoComercial-CompartirIgual 3.0 Costa Rica. Para más información envíe un mensaje a 
Iván Molina y Patricia Fumero critican los señalamientos de Kinloch al apuntar que, en el surgimiento de la comunidad política imaginada nicaragüense, se enfatizó el vínculo existente, durante el siglo XIX, entre el proyecto canalero y la constante amenaza exterior. Fue en este contexto que se creó en Nicaragua un vocabulario nacionalista y una imagen nacional. Sin embargo, este proceso no giró, únicamente, en torno a la construcción del canal interoceánico. Tal es el caso de la promoción de la Batalla de San Jacinto y del héroe José Dolores Estrada durante el período de estabilidad política de los "Treinta Años Conservadores" (1857-1893) (Molina y Fumero, 1997). La Batalla de San Jacinto, junto con el rescate de Estrada, un héroe al que se le adscribieron los valores más tradicionales de las clases subordinadas —la humildad, el valor, la lealtad y el patriotismo - facilitaron el avance del proceso de invención de la nación nicaragüense por parte del Estado (Molina y Fumero, 1997).

Para Guillermo Fernández, entre 1871 y 1930, se impulsaron desde el Estado en Nicaragua tres concepciones diferentes de lo que era la nación y la patria, y tres interpretaciones distintas sobre el pasado del país, con algunos matices contradictorios entre sí. Estas variaciones en la construcción de un discurso nacional hegemónico sobre el pasado nicaragüense están íntimamente ligadas a los diferentes proyectos políticos, económicos y sociales de nación que se impulsaron en esos años, y al fracaso de cada uno de ellos (Fernández, 2008). Por otra parte, durante el régimen de José Santos Zelaya (1893-1909) su ministro de Educación, José Dolores Gámez, publicó los libros Catecismo de Historia Patria y Catecismo de Historia de Centroamérica por medio de los que se transmitió a toda una generación de nicaragüenses un doble sentimiento de nacionalidad. Los jóvenes de la época aprendieron que su patria o país era Nicaragua y su nación, Centroamérica (Fernández, 2008).

\footnotetext{
(c) (i) (9) (2)

La Revista Estudios es editada por la Universidad de Costa Rica y se distribuye bajo una Licencia Creative Commons Atribución-NoComercial-Compartirlgual 3.0 Costa Rica. Para más información envíe un mensaje a revistaestudios.eeg@ucr.ac.cr.
} 
A un nivel teórico comparto con Wolfe (2009) la idea de que, los años trágicos de la "anarquía" - cualquiera que sea su causa - fueron una etapa de desarrollo en la maduración inevitable de la nación. Esto me lleva a plantear la hipótesis de que el rescate y la celebración del 15 de setiembre durante el siglo XIX en Nicaragua, le permitió a la elite nicaragüense dar un paso importante en la formación del Estado-nación. A diferencia del caso europeo (Hobsbawm y Ranger (2002), esta tradición cívica no se transmitió a un nivel nacional a todos los sectores subalternos a través del sistema educativo, ni se hizo en oposición a la iglesia católica, más bien contó con su apoyo debido a que esta institución quería mantener su influencia en la sociedad nicaragüense.

Durante el último cuarto del siglo XIX la clase dominante nicaragüense hizo un esfuerzo consistente por fortalecer el aparato estatal en todo el territorio nacional. El presidente José Santos Zelaya (1893-1909) se interesó por crear un proyecto político-cultural de nación. Asimismo, el cultivo del café demandaba que el Estado estableciera las condiciones económicas, políticas y sociales para su expansión. Dentro de este proyecto de modernización estatal se emitió la Constitución de 1894 que proveyó un marco legal para establecer la separación entre la Iglesia y el Estado, el derecho de propiedad y seguridad individual, la educación laica y gratuita, la formación de un ejército moderno y la anexión de la Mosquitia, entre otros logros.

A partir de la intervención estadounidense (1910-1933) el proceso de formación del Estado nicaragüense pasó a una nueva etapa. El interés geopolítico de Estados Unidos era tutelar un Estado "fuerte" que garantizara la estabilidad de la región centroamericana. Con esa intención la potencia norteamericana creó en 1911 la Recaudación General de Aduanas, en 1912 estableció el Banco Nacional, en 1917 instituyó la Alta Comisión —responsable del manejo del Presupuesto Nacional-, en 1923 creó la Ley Dodds (que era una ley electoral) y, por último, en

\section{(c) (i) (2)}

La Revista Estudios es editada por la Universidad de Costa Rica y se distribuye bajo una Licencia Creative Commons Atribución-NoComercial-CompartirIgual 3.0 Costa Rica. Para más información envíe un mensaje a 
1928 creó la Guardia Nacional. Alrededor de este marco institucional surgió y se desarrolló la dictadura de los Somoza (1936-1979) (Libro de la Defensa Nacional, 2005, p. .21-23).

Durante el referido período de ocupación estadounidense, "el Estado nicaragüense fue un protectorado manejado por instituciones y un sistema jurídico ideado para favorecer a la potencia" (Acuña, 2018, págs.15-16). Para Miguel Ayerdis las únicas efemérides de trascendencia nacional promovidas por el Estado nicaragüense durante los años de estudio eran la celebración de las fiestas de Independencia, la Batalla de San Jacinto y el 12 de octubre, Día de la Raza (Ayerdis, 2005). El presente artículo precisará esta afirmación. Aunque la gratuidad de la educación primaria estaba establecida desde la década de los ochenta del siglo XIX, esta medida no se observaba rigurosamente. Hasta los años treinta del siglo XX, cerca de $70 \%$ de la población en edad escolar era analfabeta; porcentaje que se incrementaba en las zonas rurales (Cumberland, 1978).

Fundamentado en todo lo anterior, es que el presente artículo tiene por objetivos estudiar la forma de celebración de la independencia en Nicaragua durante el período 1866-1895, determinar los conceptos políticos que se transmitían en los discursos proclamados para tal fecha y estudiar los discursos que la prensa nicaragüense emitió sobre la celebración del 15 de setiembre entre 1903 y 1928. Esta información se obtendrá de los ejemplares disponibles de Gaceta de Nicaragua, Gaceta Oficial y Diario de Nicaragua entre 1866 y 1895 y El Comercio, La Tribuna y La Gaceta de 1903 a 1928.

\section{(c) (i) (2)}

La Revista Estudios es editada por la Universidad de Costa Rica y se distribuye bajo una Licencia Creative Commons Atribución-NoComercial-CompartirIgual 3.0 Costa Rica. Para más información envíe un mensaje a 


\section{La celebración de la independencia en Nicaragua 1866-1875: igualdad,} moralización, patriotismo, unión centroamericana y trabajo

Los primeros actos de celebración del aniversario de la independencia en Nicaragua se realizaron en 1866 durante el período político denominado de los Treinta Años Conservadores (1858-1893). Esto debido a que durante los períodos de la anarquía y de la Campaña Nacional (1821-1857) no existió la estabilidad política y la capacidad económica para festejar esta fecha patria (Lanuza, 1976). Estos festejos los costeaba el Poder Ejecutivo y se realizaron en el salón del Congreso donde asistía la elite político-económica, el presidente de la República, su gabinete, los diputados, los jueces, la cúpula militar, los representantes de la iglesia católica, los intelectuales y la burocracia capitalina. La importancia de esta fiesta cívica fue que comenzó el rescate y la construcción de una celebración que ayudará a la transmisión de un sentimiento de pertenencia nacional y a la consolidación del Estado nacional. Aunque esta celebración no se propagó a un nivel nacional, el solo hecho de festejar la independencia y no a un santo o una virgen constituye a nivel mental un cambio importante. Ya en 1878 el historiador Jerónimo Pérez daba a conocer su preocupación con respecto a las diversiones tradicionales que se darían en las fiestas patronales de la ciudad de Masaya (Urbina, 2015).

El 14 de setiembre de 1866, la celebración del 15 de setiembre comenzó en la noche con la iluminación de los dos pisos del edificio del Palacio Nacional. A las 4 de la mañana del 15 hubo una detonación de cañón en honor del día patrio. Por la mañana se celebró una misa y se cantó el Te Deum en la iglesia parroquial de Managua, a la que asistieron los integrantes del gobierno, los empleados civiles y militares y la corporación municipal. Una vez terminada esta actividad la asistencia paso al salón del Congreso donde el Ministro de Relaciones Exteriores Dr. Rosalio Cortez dio el discurso conmemorativo a la fecha en estudio. La peroración que se

\section{(c) (i) (2)}

La Revista Estudios es editada por la Universidad de Costa Rica y se distribuye bajo una Licencia Creative Commons Atribución-NoComercial-CompartirIgual 3.0 Costa Rica. Para más información envíe un mensaje a 
emitió señala que la independencia provocó en Nicaragua la igualdad y el desarrollo, ya que se señala que en el país se dio el desarrollo de las facultades políticas manifestado a través de la ilustración del pueblo, en su comercio, en su industria, en su agricultura, y sobre todo en la disolución de la propiedad, y en el goce de los derechos individuales, donde no existían los privilegios personales, odiosos y contarios a la dignidad del hombre (Gaceta de Nicaragua, 22 de setiembre de 1866, p.293). Para don Rosalio la independencia significaba la soberanía nacional, la libertad del pensamiento, la inviolabilidad de la conciencia y de la palabra, la muerte del monopolio, la libertad del comercio, la inmigración de todas las razas, la invasión de todas las ideas, la introducción de todas las industrias, en pocas palabras eran: la república, la democracia y el sistema representativo (Gaceta de Nicaragua, 22 de setiembre de 1866, p.293). Este discurso oculta la realidad política del momento pues los campesinos fueron sometidos a una dura explotación económica durante un período donde el país vivió bajo una democracia censitaria.

También en 1866 el Subprefecto del distrito de Managua don Indalencio Bravo emitió un discurso en conmemoración del 45 aniversario de la independencia. En él se señala la importancia de la independencia en la formación personal del ser humano. Para don Indalencio la inteligencia y la libertad en el orden moral son los únicos elementos con que se explican el hombre y la sociedad. Como inteligente y libre, el hombre es un ser sociable, como inteligente y libre un ser independiente. Su independencia explica su personalidad; y si se ha de explicar la sociedad por el hombre, la independencia de un pueblo explica su individualidad (Gaceta de Nicaragua, 22 de setiembre de 1866, p.293). Todo este razonamiento explicaba que: “...Nicaragua en su carácter de Nación ostenta orgullosa en su pabellón tremolante la fuerza de su individualidad y el poder de su soberanía, como un consiguiente de su libertad e independencia" (Gaceta de Nicaragua, 22 de setiembre de 1866, p.293).

\section{(c) (i) (9) (2)}

La Revista Estudios es editada por la Universidad de Costa Rica y se distribuye bajo una Licencia Creative Commons Atribución-NoComercial-CompartirIgual 3.0 Costa Rica. Para más información envíe un mensaje a 
Dos años más tarde le correspondía a don Anselmo H. Rivas, quien era el Ministro de Gobernación y Guerra, dar el discurso alusivo a la fecha de estudio. El señor Rivas explica que en Nicaragua los primeros desaciertos políticos de su vida independiente determinaron una dilatada serie de desgracias que impidieron su desarrollo y su progreso, y que hicieron que el país se hallara como al principio de la independencia o en retroceso. El desgarramiento social provocado por las frecuentes convulsiones políticas, el cegamiento de las fuentes de riqueza y la desmoralización del pueblo por la influencia de malos gobiernos provocaron que entre la población no se pudiera desplegar el heroico valor y la virtud austera de los hombres que iniciaron la independencia. Para salir de esta situación era necesario tener prudencia, justicia, buena fe y perseverancia (Gaceta de Nicaragua, 19 de setiembre de 1868, p.298). Nuevamente se repite un discurso donde la moralización era fundamental para salir del atraso político.

Después del discurso anterior, las peroraciones alusivas al 15 de setiembre se volverán a emitir hasta 1874. Esta vez le tocó el turno de darlo al Ministro de Gobernación el Dr. Francisco Barberena en el Salón del Poder Ejecutivo. Para el Dr. Barberena el pueblo centroamericano tuvo patria hasta el 15 de setiembre de 1821, cuando al sacudirse el dominio español se resolvió a gobernarse por sí mismo y asumir su soberanía. También se hace un llamado a que los centroamericanos se unan para que su raza no fuera absorbida, ante una oleada de inmigración que provocaría la apertura del Canal interoceánico por el istmo de Nicaragua (Gaceta de Nicaragua, 19 de setiembre de 1874, p.306).

Otro discurso pronunciado en 1874 fue el del sacerdote P. Abelardo Obregón, cura y vicario de Managua, quien señalaba que la independencia para Nicaragua era un regalo de Dios, un don precioso no concedido a otras naciones, sino después de lágrimas y de sangre, de múltiples desastres y de innumerables víctimas

\section{(c) (i) (9) (2)}

La Revista Estudios es editada por la Universidad de Costa Rica y se distribuye bajo una Licencia Creative Commons Atribución-NoComercial-CompartirIgual 3.0 Costa Rica. Para más información envíe un mensaje a revistaestudios.eeg@ucr.ac.cr. 
(Gaceta de Nicaragua, 19 de setiembre de 1874, p.307). La iglesia católica durante los Treinta Años Conservadores fue obligada a someterse a la hegemonía del Estado. En estos años se anuló el pago del diezmo, se declaró libre la observancia del domingo, se fijaron montos para el pago de servicios religiosos y de primacías, la educación se hizo libre, y se ordenó la expulsión de los jesuitas. "Pese a la oposición del obispo, la Iglesia fue obligada a vender algunas de sus tierras incultas o sobre las que no tenía título de propiedad" (Teplitz, 1974, p.77).

El último texto que se leyó sobre el 15 de setiembre fue el del Ministro de Instrucción Pública, don Anselmo H. Rivas, en el Salón del Congreso. Don Anselmo en su discurso dirigido a los jóvenes y niños presentes en el acto de celebración de la independencia, les decía que en el futuro serían los que regirían los destinos de Nicaragua, y a mejorar la condición de la familia centroamericana, que algún día volverá a formar un todo compacto. A los preceptores de los niños les recordaba su responsabilidad de sembrar la semilla del patriotismo en ellos, porque ellos se encargarían de defender los fueros de la patria. Era necesario que combatieran en sus alumnos los sentimientos de la envidia y de la vanidad (Gaceta de Nicaragua, 19 de setiembre de 1874, p.308). Este discurso es importante porque a los niños y jóvenes que asistieron a esta celebración se les hace ver la importancia de la defensa de la patria.

Para 1875 nuevamente le correspondió emitir el discurso referente al 15 de setiembre a don Rosalio Cortéz, quien ahora era el Ministro de Gobernación. Para don Rosalio, era enorme la diferencia entre la cifra de los habitantes de Nicaragua y la de los europeos o estadounidenses, entre la cifra del capital nicaragüense y la de esos pueblos. Era una ridiculez querer parodiar a esos pueblos, y torturar a los connacionales para que alcancen un progreso a donde no llegaran sin caer antes desfallecidos de extenuación. Lo que impulsaría a la nación nicaragüense al progreso serían la tolerancia política, la fraternidad, el trabajo constante y la 
economía pública y privada. Ante esto, el Ministro Cortéz afirma que la independencia había puesto en las manos de los nicaragüenses el bien y el mal y que había que saber escoger (Gaceta de Nicaragua, 18 de setiembre de 1875, p. 375). Asimismo, en 1875 el cura P. Abelardo Obregón, pronuncia otro discurso donde hace un llamado a la unión centroamericana: "Si queremos conservar la independencia, preciso es que todos los Estados se unan en una sola nación: los pueblos lo quieren, los diferentes gobernantes de los Estados lo desean, las necesidades públicas lo demandan, i sobre todo lo exige la seguridad, la conservación i la dignidad de la independencia, don precioso de la Providencia Divina que hoy celebramos de una manera aislada i que algún día se oirá victorear con la voz robusta i sonora de la República de Centroamérica" (Gaceta de Nicaragua, 18 de setiembre de 1875, p.375).

\section{La celebración de la independencia en Nicaragua 1877-1895: educación, rescate de la Campaña Nacional y progreso}

En 1877 el Ministro de Gobernación Lic. Agustín Duarte, argumenta que el país estaba en la senda de la regeneración, poseía una legislación que armonizaba con la justicia y con el sistema representativo. La instrucción difundiría en las masas, la luz indispensable para seguir sin vacilar en el camino del bien y para que no prestaran atención a instigaciones que, con el falso pretexto de conducirlas a un fin laudable, tienden a extraviarlas y a colocarlas en inminente peligro de llegar a la relajación de los vínculos sociales (Gaceta de Nicaragua, 18 de setiembre de 1877 , p.339). Para brindarles a los nicaragüenses una prosperidad completa era indispensable la cooperación de todos los ciudadanos, en el sentido de fortalecer el orden, de afianzar el verdadero respeto a la ley y de honrar el trabajo (Gaceta de Nicaragua, 18 de setiembre de 1877, p.340).

\section{(c) (i) (9) (2)}

La Revista Estudios es editada por la Universidad de Costa Rica y se distribuye bajo una Licencia Creative Commons Atribución-NoComercial-CompartirIgual 3.0 Costa Rica. Para más información envíe un mensaje a 
En la alocución del señor Duarte es necesario detenerse en dos aspectos: el llamado al respeto al orden y la ley y el trabajo de los nicaragüenses. Sobre el primer punto, se sabe que el uso de la fuerza, como instrumento en las luchas políticas, se mantuvo durante el período conservador. Con la excepción de Evaristo Carazo (1887-1889), todos los presidentes nicaragüenses, desde Tomás Martínez a Roberto Sacasa, debieron enfrentar revueltas armadas de diversa intensidad (Esgueva, 1999). El presidente Pedro Joaquín Chamorro (1875-1879), fundador del Partido Conservador, debió hacerle frente a una cantidad importante de rebeliones como indican Escobar (1968) y Vargas (2008).

Con respecto al aspecto laboral, la escasez de mano de obra fue un problema fundamental en la economía. Para Delgado, en su afán de terminar con éste inconveniente, los conservadores dictaron leyes que obligaban a los campesinos a cumplir con sus contratos y a pagar sus deudas de trabajo. La legislación emitida en este sentido, recrudeció el trabajo forzoso y con ello se fortalecieron las formas pre capitalistas de trabajo (Delgado, 1974). Para Collado (1988) el aumento a las invasiones a las tierras comunales, así como la compulsión para que los indígenas trabajaran gratuitamente en la construcción de caminos, líneas telegráficas o para que se engancharan en las fincas ocasionó importantes levantamientos indígenas en 1881. Jeffrey L. Gould (1997) ha señalado que en la época de la rebelión indígena de Matagalpa en 1881 nació el mito de "la Nicaragua Mestiza": un discurso oficial que describe a este país como uno étnicamente homogéneo donde el elemento indígena es desvalorado.

En los actos oficiales de celebración de la independencia de 1878 se tiene que, el 14 de setiembre en la madrugada, la música marcial dio toques de diana en la capilla donde yacían los restos del General José Dolores Estrada. Al mismo tiempo una detonación de cañón fue hecha como saludo a vigésimo segundo aniversario de la Batalla de San Jacinto. A las 12 del mediodía el Cuerpo Militar

\section{(c) (i) (2)}

La Revista Estudios es editada por la Universidad de Costa Rica y se distribuye bajo una Licencia Creative Commons Atribución-NoComercial-CompartirIgual 3.0 Costa Rica. Para más información envíe un mensaje a 
visito al Presidente de la República don Pedro Joaquín Chamorro. A las siete de la noche los edificios públicos fueron iluminados. Luego se efectuó una exhibición de fuegos pirotécnicos que duró hora y media. Posteriormente, los miembros de la municipalidad de Managua y gran concurrencia municipal recorrieron las calles capitalinas junto a una orquesta, vitoreando la memoria de José Dolores Estrada y de sus soldados. El paseo duró hasta muy avanzadas horas de la noche, no obstante, la fuerte lluvia que caía. El uso que el gobierno de don Pedro Joaquín Chamorro hace de la figura de José Dolores Estrada y de la Batalla de San Jacinto pretende echar mano de dos elementos identitarios de unidad nacional, con los cuales apaciguar los alzamientos políticos en su contra.

El día 15 fue saludado en la mañana con salvas de artillería. A las 12 del mediodía los miembros del gobierno y la burocracia y vecinos notables de la capital, se dirigieron del Palacio Nacional a la iglesia parroquial para asistir al solemne $\mathrm{Te}$ Deum. En la iglesia pronunció un discurso referente a la fecha que se festejaba, el cura don Atilano A. Lozano, oriundo de México. Una vez concluido el Te Deum la concurrencia se dirigió al salón del Congreso, donde se procedió a la lectura del Acta de independencia y el discurso oficial. Pese a que el discurso oficial to pronunció el Ministro de Gobernación Lic. Agustín Duarte, también tomaron la palabra el Prefecto del departamento de Managua don Francisco D. Avilés, el Juez de Primera Instancia Lic. Pascual Fonseca, el Secretario Municipal de Managua don José Godoy, el miembro de Partido Conservador don Juan M. Arce, el padre Atilano Lozano y el encargado de la redacción de la Gaceta Oficial. Finalizado el acto la concurrencia pasó a tomar un refresco. En la tarde se realizó el paseo militar encabezado por el Presidente de la República que concluyó en un simulacro de batalla en la plaza principal. En la noche se dio un suntuoso baile en el Palacio Nacional, durando hasta las 3 de la mañana del día siguiente (Gaceta Oficial, Martes 17 de setiembre de 1878, p.308).

\section{(c) (i) (2)}

La Revista Estudios es editada por la Universidad de Costa Rica y se distribuye bajo una Licencia Creative Commons Atribución-NoComercial-CompartirIgual 3.0 Costa Rica. Para más información envíe un mensaje a 
En 1878 nuevamente el Lic. Duarte emite el discurso oficial de éste año, haciendo énfasis de que los problemas de Nicaragua y de Centroamérica se resolverán con trabajo: "Un poco mas de buen sentido, de abnegación i de trabajo, i eso bastará para que los elevados propósitos que hoi formemos estingan la fuente jeneradora del mal, i para que podamos realizar las promesas de la fortuna, desarrollando el poder productor que aun se conserva latente en nuestros trabajados pueblos...Procediendo así, lograremos que no se repitan los frecuentes estravios que han convertido el rico suelo de la América Central en campo de batalla, i acercarnos poco á poco á la deseada perfeccion; hasta que lleguemos á tener la dicha de decir con la gran República: este pueblo es la encarnacion de la Libertad i del Trabajo" (Gaceta Oficial, Martes 17 de setiembre de 1878, p.306).

Para 1880 el discurso del 15 de setiembre lo dio el Subsecretario del Ministerio de Gobernación don Agustín García. En su reflexión don Agustín resalta que el atraso de Nicaragua se debía a los errores políticos, a las divisiones y a las luchas fratricidas. Todo esto había impedido que se explotaran las inmensas riquezas naturales del país. Sin embargo, se acota que el país se estaba desarrollando por la existencia del telégrafo, del ferrocarril, las carreteras nacionales, el sistema postal, la educación, las instituciones públicas y la eventual construcción de un canal interoceánico (Gaceta Oficial, 18 de setiembre de 1880, págs.330-331). Acerca de lo expuesto por el señor García debe señalarse que, acompañando al proceso de consolidación estatal, el relativo crecimiento de la economía mediante la exportación de ganado y añil y el desarrollo del café, exigían innovaciones como el tendido de vías férreas y líneas telegráficas, la apertura de tierras baldías y la generalización del trabajo forzoso. Todo esto fue posible porque existía un Estado promotor de la agricultura, señala Collado (1988).

Los actos de festejo de la independencia de 1884 comenzaron en la mañana del día 14, con la visita que el cuerpo militar capitalino le hizo al presidente de la 
República. En la noche se realizó en la plaza principal una exhibición de fuegos artificiales que duró cerca de dos horas. Especialmente causó agrado, la figura de una locomotora que corría de un punto a otro, despidiendo luces de diversos colores al mismo tiempo que imitaba el toque de la campana y el silbido de una de verdad. El día 15 se realizó el acto oficial pronunciando el discurso en nombre del gobierno, el Subsecretario del Ministerio de Gobernación el Lic. Bruno H. Buitrago. Posteriormente, en otro de los salones del Palacio Nacional, se leyeron los discursos del General Dr. Ramón Sárria, de don Gregorio C. del Valle y una inspirada composición poética del joven Felipe Ibarra. También tomó la palabra el poeta Rubén Darío quien improvisó unas estrofas relativas a la ocasión.

Enseguida se procedió a la distribución de premios a los alumnos de todas las escuelas de Managua. Este acto fue presidido por el Ministro de Instrucción Pública, Lic. Francisco Castellón. En esta actividad también pronunció un discurso en nombre de la municipalidad, el Alcalde Primero don Luis E. López. A las cuatro de la tarde comenzó el paseo Militar, encabezado por el Ministro de la Guerra, Coronel Joaquín Elizondo, terminando a las seis en la plaza principal con un simulacro de batalla. Para este año se sabe que el aniversario de la independencia se estaba celebrando en la mayor parte de las poblaciones del país (Gaceta Oficial, 20 de setiembre de 1884, p.283). En el discurso del señor Buitrago se apunta que, a pesar de las guerras fratricidas, el país había experimentado durante el período conservador ciertos avances debido al telégrafo, el ferrocarril, las escuelas, las leyes sabias, el honor y la propiedad. Si Nicaragua quería seguir avanzando debía de vivir en paz (Gaceta Oficial, 20 de setiembre de 1884, p.282). Debe aclarase que no existen pruebas de que en este año la celebración de la independencia se celebrara en todo el país. Las rebeliones y alzamientos políticos durante el período conservador señalan que este no era un grupo homogéneo y que el uso de la fuerza no había desparecido en la vida política.

\section{(c) (i) (9) (2)}

La Revista Estudios es editada por la Universidad de Costa Rica y se distribuye bajo una Licencia Creative Commons Atribución-NoComercial-CompartirIgual 3.0 Costa Rica. Para más información envíe un mensaje a 
Las fiestas del aniversario patrio de 1885 iniciaron a las 4 de la mañana del día 14 de setiembre, con la diana que la Banda Marcial tocó ante la tumba del General José Dolores Estrada. Al mismo tiempo un cañón saludaba con salvas el comienzo de las fiestas. A las 6 de la mañana se izó la bandera nacional, haciendo la artillería los honores de la ordenanza, y adornando la capital con miles de banderas y colgaduras que ostentaban los colores nacionales. A las doce del mediodía el Cuerpo Militar pasó a saludar al Presidente de la República don Adán Cárdenas. A las 4 de la tarde el cuerpo de artillería hizo ejercicios de tiro al blanco. Lo más significativo de estas celebraciones fue que a las 5: 30 de la tarde, se dio un magnifico banquete en honor de los veteranos de la Batalla de San Jacinto. A las 7: 30 se dio una recepción oficial en la Mayoría General donde una inmensa muchedumbre se aglomeraba a las puertas. Seguidamente se quemaron juegos pirotécnicos, concluyendo la fiesta con un paseo que salió a las 10 de la noche del Cuartel de Artillería. El día 15 la Banda Marcial tocó una diana en la casa del presidente. Un cañón emitía cada treinta minutos detonaciones de salva. A las 12 del mediodía se cantó en la Iglesia parroquial un solemne Te Deum. A las 12: 30 del medio día el Presidente y sus ministros ingresaron al Salón del Congreso donde se dio el discurso oficial por parte del diputado J. D. Rodríguez. Posteriormente, se ofreció un refresco a los concurrentes a este acto y al pueblo. A las 5 pm, se efectuó el paseo militar y por la noche hubo un gran baile en el Palacio Nacional (Gaceta Oficial, 19 de setiembre de 1885, págs.275-276). Es en este año que el pueblo capitalino es hecho partícipe de la celebración del 15 de setiembre.

Con respecto a la alocución del diputado Rodríguez, éste explicaba que en la búsqueda de la libertad no se tomó en cuenta el estado intelectual del pueblo, sus hábitos, sus costumbres, sus necesidades y sus vicios. Esto trajo como consecuencia las pasiones, las rivalidades y las ambiciones. El espíritu del trastorno político solo se retiraría por la luz de la instrucción y del bienestar, hijo

\section{(c) (i) (9) (2)}

La Revista Estudios es editada por la Universidad de Costa Rica y se distribuye bajo una Licencia Creative Commons Atribución-NoComercial-CompartirIgual 3.0 Costa Rica. Para más información envíe un mensaje a 
del trabajo. Solo con estas condiciones podría cimentarse en el país la libertad. Para alcanzar el anhelado engrandecimiento nacional el gobierno debía fomentar la felicidad de los ciudadanos y garantizar la seguridad. Los ciudadanos, en cambio, debían sostener las instituciones y el gobierno (Gaceta Oficial, 19 de setiembre de 1885, págs.273-274). Lo expuesto en este discurso expone una visión de clase y pretende ocultar las fuertes divisiones al interno del grupo conservador, alegando que era el pueblo el culpable de esto. Anteriormente se ha hablado del carácter elitista del poder de los conservadores. La mayor parte de la población nicaragüense vivía en condiciones de analfabetismo, miseria y aislamiento y no tenía acceso al poder. Este discurso legitima las abismales diferencias sociales y económicas creadas por los conservadores, poniendo como remedio a la crisis del pacto oligárquico el uso del trabajo forzado entre los campesinos. El trabajo era la panacea del cual se derivaban la educación y el bienestar, elementos indispensables para que Nicaragua fuera un país libre. Según se nota, la "pertenencia colectiva" que se promueve como un destino compartido carece de la percepción necesaria por parte de los sectores dominados, debido a que carecen de una verdadera integración física, social y cultural, especialmente entre los sectores campesinos (Bagú, 1975).

Sobre los festejos de 1886 no se da mucha información (Gaceta Oficial, 18 de setiembre de 1886, p.307). Esta vez el discurso lo dio el Dr. Tomas Ayón, quien aparte de explicar el proceso histórico que llevó a la independencia, refiere que el solo el gobierno constitucional en que la voluntad del pueblo ejerce su poder soberano, responde perfectamente a los derechos del hombre. Los próceres de la independencia habían dejado al país dos grandes beneficios: la emancipación de España y la democracia (Gaceta Oficial, 18 de setiembre de 1886, p.307). Al año siguiente la reflexión oficial la dio a conocer el Lic. Pedro González, donde argumenta que el desarrollo del país proviene desde 1858 con la llegada al poder de los gobiernos conservadores que habían consolidado las libertades públicas, 
ensanchado la instrucción popular y construyendo nuevas vías de comunicación (Gaceta Oficial, 17 de setiembre de 1887, p.468).

Los festejos patrios de 1888 comenzaron el 14 de setiembre a las ocho de la noche, con unos juegos pirotécnicos en la plaza principal, después varios músicos dieron serenatas por toda la ciudad, en medio de una fuerte lluvia. Luego hubo una velada en el Club Social. El 15 por la mañana hubo una reunión en el Palacio Nacional a la cual asistieron el Presidente de la República don Evaristo Carazo, acompañado de sus ministros y varios empleados públicos. Luego se trasladaron a la Iglesia parroquial para la celebración del Te Deum de rigor. El Prefecto de Managua tuvo la idea de llevar a ese acto a las niñas de las escuelas managüenses. Estas tenían en las manos banderitas con los colores nacionales, la mayor parte bordadas por ellas mismas (Gaceta Oficial, 19 de setiembre de 1888, págs.474-475). Esta identificación de la celebración de la independencia entre los escolares no se repitió en los años posteriores. Aunque desde la década de los ochenta del siglo que aquí se estudia, se estableció la gratuidad de la educación primaria, esta medida no se observada rigurosamente. Hasta los años treinta del siglo XX, cerca del $70 \%$ de la población en edad escolar se encontraba en el analfabetismo, siendo esta cifra mayor en las zonas rurales, según Cumberland (1978).

En este año el discurso lo expresó el Lic. David Osorno quien a un nivel general señaló lo mismo que su predecesor (Gaceta Oficial, 19 de setiembre de 1888, págs.473-474). En las fiestas de la independencia de 1889 se repitió lo mismo que en los años anteriores, resaltando el hecho de que el día 15 en la ciudad de Chinandega se llevó a cabo una exposición departamental de productos agrícolas, artísticos e industriales, además de otras fiestas ordenadas por las autoridades y vecinos (Gaceta Oficial, 18 de setiembre de 1889, págs. 570-571). Según se nota el festejo de la independencia en Chinandega aparte de celebrar la independencia 
nacional promovía también la identidad agrícola que el Estado desarrollaba. En 1889, le tocó la oportunidad de emitir el discurso oficial al Ministro de Gobernación Dr. D. Modesto Barrios, quien resaltó la gesta heroica de José Dolores Estrada. Sin embargo, la emancipación del pueblo nicaragüense estaba incompleta debido a que debía liberarse de otras servidumbres, sobre todo de las pasiones políticas (Gaceta Oficial, 18 de setiembre de 1889, p.569).

Los actos y las alocuciones oficiales de 1890 (Gaceta Oficial, 17 de setiembre de 1890, págs.303-304), de 1892 (Gaceta Oficial, 17 de setiembre de 1892, págs.13), 1893 (Gaceta Oficial, 17 de setiembre de 1893, p.3) y de 1897 (Gaceta Oficial, 17 de setiembre de 1897, págs.1-2) no aportan nada nuevo. Sin embargo, en la diatriba de 1895 leída por el Dr. José Madriz al referirse a las diferencias entre anglosajones y latinos en América, afirmaba que: "Por qué no usamos de la libertad como los americanos del norte? ¿Por qué éstos, que tuvieron menos motivos para desear y declarar su independencia, saben ser más libres que nosotros? No busquemos la causa de la diferencia en la sangre que circula en nuestras venas; no nos envilezcamos con la idea de que somos esencialmente inferiores á otros hombres...La causa eficiente de nuestros males está en la defectuosa educación que recibimos de la Madre Patria. Los americanos del norte habían aprendido á ser libres bajo el régimen colonial: Inglaterra fue para ellos madre y maestra: lección objetiva, enseñanza practica les dió, y educó hijos en vez de formar esclavos" (Diario de Nicaragua, 18 de septiembre de 1895, p.2). Asimismo, afirma que el gobierno debe de cuidar al pueblo: "hay que aliviarlo de su yugo...el día que se ilustre no será más víctima del amo y del sacerdote" (Diario de Nicaragua, 18 de septiembre de 1895, p.3). Durante el gobierno de José Santos Zelaya (1893-1909) se dio un fuerte apoyo a la educación primaria, ya que al concluir su período había un total de 643 escuelas primarias. En relación a las 193 que había en 1894 (Rodríguez, 1998, p.136). Asimismo, Zelaya impulsó una serie de medidas del marco jurídico institucional de la Revolución Liberal con la 
Constitución de 1894 y la promulgación de códigos y leyes que ordenaron el funcionamiento estatal y social y establecieron la separación entre la Iglesia y el Estado. Introdujo el derecho de propiedad y seguridad individual, la educación laica y gratuita, y se crearon instituciones gubernamentales que facilitaron las gestiones para la producción y el comercio, y la conformación de un ejército moderno. Además, del voto universal de los varones, directo y secreto. Empero, durante su mandato el país vivió en estado de sitio por lo que obtuvo poderes absolutos y gobernó como dictador, lo que hizo que las medidas democratizadoras se quedaran en el papel, señala Herring (1962).

Con el fin de comparar la celebración de la independencia en Nicaragua con respecto al resto de los países centroamericanos, se tiene que en Costa Rica entre 1899 y 1921 la fiesta escolar fue el ritual más importante de la fiesta conmemorativa de la independencia en este país, principalmente porque transmitió un sentimiento de pertenencia nacional entre los escolares a un nivel nacional. Después del centenario de la independencia el ritual nacionalista también transmitió la observación de prácticas saludables de vida. La fiesta escolar del 15 de setiembre fue el mejor medio para propagar y asentar la práctica del canto del Himno Nacional. Por el contrario, en países como El Salvador y Guatemala, la fiesta del 15 de setiembre tenía la ambigüedad de ser una conmemoración centroamericana y no local hasta entrado el siglo XX como explica Díaz, en numerosos textos como los del 2005, 2007 y 2011. Sin embargo, Carlos Gregorio López (2005) apunta para el caso salvadoreño que, en el plano oficial, para finales del siglo XIX, en El Salvador se había avanzado considerablemente en la institucionalización de las fiestas patrias. Aunque estas aún dependían de la iniciativa estatal, algunos sectores sociales se estaban apropiando de ellas; como los artesanos y obreros. Estos fueron muy receptivos al discurso liberal y retomaron valores asociados a la educación, la moral, el trabajo y el ahorro, juntamente con una disposición al civismo.

La Revista Estudios es editada por la Universidad de Costa Rica y se distribuye bajo una Licencia Creative Commons Atribución-NoComercial-CompartirIgual 3.0 Costa Rica. Para más información envíe un mensaje a 


\section{La celebración de la independencia en la prensa nicaragüense (1903-1928)}

El diario El Comercio reprodujo el discurso del diputado don Adolfo Vivas con motivo del festejo del 15 de septiembre de 1903. Este discurso, de tipo nacionalista, refiere que:

"el pueblo nicaragüense agradece y admira la ofrenda que recibió de manos de sus libertadores, ofrenda que aspira a conservar a través de los años en toda la pureza con que fue entregada por aquellos insignes varones. Además, el señor Vivas dice que no se extinguirá este sentimiento que repercute en cada pecho con todas las vibraciones de la gratitud, y que ha de hacer, bajo el influjo del trabajo, de la luz de la enseñanza y de los bellos principios republicanos, la felicidad y la prosperidad de la patria (El Comercio, 17 de setiembre de 1903, p.2).”

El discurso anterior reitera lo señalado sobre el festejo de la Independencia en el siglo XIX, donde se ponía el acento en el término trabajo, que dentro del vocabulario político nicaragüense era la panacea de la cual se derivaban la educación y el bienestar, elementos indispensables para que en Nicaragua se asentara la libertad (Urbina, 2015a). Esta peroración, única que se emitió en una celebración oficial de las fechas patrias, tuvo un carácter exclusivo debido a que se realizó en la Casa Presidencial, lugar al que asistía solamente la élite políticoeconómica. Empero, a diferencia del período entre 1866 y 1895, a principios del siglo XX la celebración de la Independencia se hizo sin la participación de la Iglesia católica, lo que se explica como consecuencia de la legislación anticlerical del régimen de José Santos Zelaya. El discurso del diputado Vivas no se emitió en un acto cívico escolar — vía idónea para ser apropiado y reelaborado— debido al débil sistema educativo nicaragüense, del cual se hablará más adelante con base en Hobsbawm (1991), Smith (1997) y Ayala (2008).

\section{(c) (i) (2)}

La Revista Estudios es editada por la Universidad de Costa Rica y se distribuye bajo una Licencia Creative Commons Atribución-NoComercial-CompartirIgual 3.0 Costa Rica. Para más información envíe un mensaje a 
La celebración del 15 de setiembre de 1906 fue utilizada para la develación del busto del ex presidente de la República Evaristo Carazo (1887-1889). Cerca del monumento se encontraba el jefe político, coronel Ignacio Zambrana, los miembros de la corporación municipal de Rivas, el directorio del Club Liberal Nacionalista: el general don Isidro Urtecho, comisionado de la municipalidad de Granada; el general don Juan Bautista Sáenz, por las de Managua, Chinandega y Carazo, el ingeniero don José C. Muñoz, por la de Masaya, y muchos vecinos principales. En su discurso, el señor Urtecho resaltó las cualidades de don Evaristo Carazo:

"No fue la vida de Carazo de relumbrón. Hombre de trabajo, ante todo, adquirió en él lo que jamás niega al que sabe emprenderlo con inteligencia, honradez y sobriedad, cualidades que unidas en él a un carácter sencillo y afable, le dieron desde muy temprano esa popularidad que conservó siempre; y sobre todo, en el trabajo fue donde adquirió ese sentido práctico que tanto le distinguió, y que más tarde llevó con mucho provecho a las altas esferas del poder (El Comercio, 14 de setiembre de 1906, p.2).

Las características conferidas a Carazo son las mismas que se le atribuyen a José Dolores Estrada: la humildad, el valor, la lealtad y el patriotismo, las cuales forman el arquetipo del ser nicaragüense (Molina y Fumero, 1997, p.27). Este discurso tiene como objetivo ocultar la división jerárquica y la existencia de fuerzas disgregadoras que obstaculizaban la constitución de un poder central, lo cual se empezó a lograr con el régimen de José Santos Zelaya; es decir, tardíamente frente al resto de los países centroamericanos (salvo Honduras). Sobre la figura de don Isidro Urtecho debe decirse que fue un destacado militar, diplomático, político y escritor conservador nicaragüense.

\section{(C) $(\Theta \odot$}

La Revista Estudios es editada por la Universidad de Costa Rica y se distribuye bajo una Licencia Creative Commons Atribución-NoComercial-CompartirIgual 3.0 Costa Rica. Para más información envíe un mensaje a revistaestudios.eeg@ucr.ac.cr. 
En el artículo "Los héroes que limpiaron la bandera", Juan Ramón Avilés se preguntaba: "si los escolares en su juramento a la bandera nacional, sabían que si podían hacer ese acto era porque el ínclito José Dolores Estrada, al reconquistarla, borró la estrella roja que William Walker le había puesto en el centro como estigma de esclavitud. Era de extrañar que no existiera un monumento ni un himno para los héroes de la Batalla de San Jacinto (La Tribuna, 14 de setiembre de 1918, p.2)". El texto concluye con la súplica de que los escolares nicaragüenses que juraran fidelidad a la bandera nacional, supieran en verdad defenderla, como Andrés Castro, como Francisco Gómez, héroes ejemplares del antiguo patriotismo, cuando los hombres eran hombres y no esclavos afortunados.

Pese a que en el artículo anterior se rescata el patriotismo de los héroes de la Batalla de San Jacinto, éste no fue secundado por escritos de otros intelectuales. Lo expuesto en el texto confirma lo señalado por Frances Kinloch (1999) en el sentido de que en Nicaragua la expulsión de William Walker no ayudó a consolidar un proyecto de nación. La influencia de la llustración estableció entre los intelectuales un ideal de inferioridad étnica, sobre todo para los sectores subalternos, y dejaron para sí el papel de propagadores de la civilización europea, aunque después de casi treinta años de transitar en la anarquía la élite política comenzó a dudar de su capacidad para establecer gobiernos estables, lo cual "atribuyeron a la herencia cultural española e, incluso, a la sangre de sus ancestros" (Memorias del IV Simposio Panamericano de Historia, 2001, p.198).

El respeto a los símbolos patrios se manifestó en 1918 con la declaratoria como himno nacional del que, escrito en sol mayor, se ejecutaba en aquel momento en el país (La Gaceta, 30 de diciembre de 1918, s.p.). Para 1922 se acuerda que siempre que se enarbolara y bajara el pabellón en las fiestas cívicas nacionales sería saludado con veintiún cañonazos. Era obligatorio para todos los ciudadanos 
de la República descubrirse y ponerse de pie cuando oyeran tocar el himno nacional o cuando pasara el pabellón en manos de un oficial del Ejército, en desfile; los militares armados presentarían su arma y los francos deberían cuadrarse (La Gaceta, 9 de agosto de 1922, s.p.).

Según se ha evidenciado, fue durante el periodo de ocupación que el Estado nicaragüense comenzó a demostrar cierto interés en la transmisión de un sentimiento de pertenencia nacional a través del fomento del culto a los símbolos patrios. No se dio a un nivel nacional debido a que durante la administración estadounidense dejaba a la educación formal e informal un apoyo exiguo, como indican Rodríguez (2005) y Gobat, (2005). Para el caso de las diversiones públicas, en vez de ser usadas para transmitir un sentimiento de pertenencia nacional lo fueron para mantener la situación de ocupación militar (Urbina, 2015b).

\section{En 1925 La Tribuna señala que:}

"En Nicaragua por desgracia, tanto en el hogar como en las escuelas y en todas partes, el culto a la patria no existe; y de allí proviene que el sentimiento predominante entre los ciudadanos es el del primitivo egoísmo, que solo inspira la idea de lucha y de sacrificio por la propia individualidad y por los propios intereses, pero que permanece indiferente ante los peligros y los sufrimientos del pro común. Además, indica que, en la lucha por la segunda independencia, nuestros mayores dieron pruebas de valor en los combates, de paciencia en la adversidad, de constancia en los reveses, de fortaleza en las privaciones, todo esto los ponía en un nivel muy superior al de sus descendientes, entre los cuales unos habían traído sobre la patria la esclavitud económica y política. Nicaragua estaba a merced del capitalismo extranjero, que continúa explotándola sin misericordia, y de los políticos profesionales de los partidos Liberal y Conservador que se disputan el predominio del poder para sacar las ventajas consiguientes a las ruinosas 
negociaciones con los explotadores de afuera (La Tribuna, 13 de setiembre de 1925, p.2)".

En este texto se alude al poco civismo de los sectores populares nicaragüenses quienes, al no tener una inclusión efectiva en la nación, no podían progresar. Asimismo, sobresale un discurso donde se trazan metas colectivas en beneficio del bien común, lo que otorga un sentido ulterior a las acciones y a las constricciones cotidianas de los sectores subalternos (Donoso, 2010).

Sobre el texto anterior Iván Molina y Patricia Fumero (1997) han señalado que, a finales del siglo XIX en Nicaragua, se construyó un vocabulario nacionalista y una imagen de nación que tuvo como ejes el canal interoceánico, la Batalla de San Jacinto y el héroe nacional José Dolores Estrada. Pese a esto, Acuña Ortega ha enfatizado que: "El Estado creado por los conservadores dejó, por tanto, una centralización política incompleta y, además, poco se ocupó de los problemas de su legitimación, es decir, poco avanzó en el proceso de invención de la nación" (Acuña, 2018, p.21).

El 14 de setiembre de 1928 La Tribuna resalta que: "Nicaragua se encuentra sometida al mismo extranjero que fue impotente para subyugar a nuestros abuelos, que se juntaron, olvidando sus pasiones y sus rencores, para rechazar al filibustero; pero que ahora, encontrando degenerados a los descendientes de aquellos héroes, explota esa degeneración, los hace despedazarse unos a otros (La Tribuna, 14 de setiembre de 1928, p.1)". Acerca del 15 de setiembre de ese año, el mencionado periódico aclara que en 1821 se rompieron las cadenas con España, pero que en 1928 las remachaba con inaudita crueldad una poderosa nación que no habla nuestra lengua, menosprecia nuestra raza y no contempla a Dios bajo el mismo prisma con que los nicaragüenses lo hacían.

\section{(c) (i) (2)}

La Revista Estudios es editada por la Universidad de Costa Rica y se distribuye bajo una Licencia Creative Commons Atribución-NoComercial-Compartirlgual 3.0 Costa Rica. Para más información envíe un mensaje a 
Debe acotarse lo que Isabel de León ha señalado sobre los discursos emitidos por los intelectuales dominicanos durante la ocupación estadounidense de 1916 a 1924, en el sentido de que "el antiimperialismo constituyó, principalmente, una postura de carácter nacionalista y culturalista. Es decir, luchar contra el imperialismo significó, ante todo, defender la nación, defender su independencia y soberanía políticas y económicas y, con ello, garantizar la conservación de esa raigambre hispánica que, supuestamente, la definía” (de León, 2015).

\section{Conclusión}

El festejo de la independencia en Nicaragua entre 1866 y 1895, fue una celebración que tuvo un carácter exclusivo debido a que se realizaba en el salón de Congreso y al cual asistía la elite político-económica. Su centro de celebración fue la ciudad de Managua, centro neurálgico y coordinador de la economía agrícola nacional, aunque al final del período de estudio otros centros económicos importantes del país comienzan a festejar esta fecha patria, promoviendo también la identidad agrícola que el Estado desarrollaba.

Los contenidos políticos que se transmitieron en estos actos, se pueden dividir en dos períodos, el primero corresponde a los años de 1866 a 1875, donde la independencia había traído la igualdad entre los nicaragüenses, pero estos debían de moralizarse, practicar el patriotismo y el trabajo con el fin de cimentar la estabilidad política. Asimismo, se añoraba la llegada de la unión centroamericana. Entre 1877 y 1895 los discursos conmemorativos del 15 de setiembre añaden conceptos políticos que destacaban el papel "liberador" de la educación. Promovían la unidad nacional y la regeneración étnica de los nicaragüenses, pues se rescata el protagonismo del héroe nacional José Dolores Estrada y de la Campaña Nacional. Asimismo, se exalta el progreso económico y la estabilidad política traída por los gobiernos conservadores.

\section{(c) (i) (2)}

La Revista Estudios es editada por la Universidad de Costa Rica y se distribuye bajo una Licencia Creative Commons Atribución-NoComercial-CompartirIgual 3.0 Costa Rica. Para más información envíe un mensaje a revistaestudios.eeg@ucr.ac.cr. 
Estas peroraciones también sirvieron para manifestar una visión clasista y mantener la forma de dominación imperante. Durante el siglo XIX la mayor parte de la población nicaragüense vivía en condiciones de analfabetismo, miseria y aislamiento y no tenía acceso al poder. Estos discursos legitimaron las abismales diferencias sociales y económicas creadas por los conservadores, poniendo como remedio a la crisis del pacto oligárquico el uso del trabajo forzado entre los campesinos. El trabajo era la panacea del cual se derivaban la educación y el bienestar, elementos indispensables para que en Nicaragua se asentara la libertad. La iglesia católica —dentro de su papel de institución subordinada al Estado- también participó en la celebración de la independencia emitiendo dos discursos, en el primero señalaba que esta era un regalo de Dios y en el segundo promovía la unión centroamericana.

Los textos emitidos por los intelectuales nicaragüenses en la prensa sobre las celebraciones del 15 de setiembre durante el período 1903-1928, son, a nivel general, del tipo nacionalista, debido a que hablan en nombre del conjunto de la colectividad a la cual dicen representar, lo que les da un carácter inclusivo. Ellos exponen las diversas influencias político-culturales que existían en la intelectualidad de esa época para abordar el tema de la identidad nacional y analizar los principales problemas por los que atravesaba Nicaragua, principalmente el de la ocupación estadounidense. Transitan entre una postura nacionalista y una antiimperialista. En estos discursos se publicaron conceptos que van desde la conservación histórica de esta fecha, la preservación de los rasgos identitarios de los nicaragüenses, el papel de la Batalla de San Jacinto en la exaltación de la imagen de los nicaragüenses como conjunto social, el papel del faccionalismo político y las ansias de poder de los partidos Liberal y Conservador, la influencia de esto en la degeneración sociopolítica de Nicaragua y, por último, la

\section{(C) $(00$}

La Revista Estudios es editada por la Universidad de Costa Rica y se distribuye bajo una Licencia Creative Commons Atribución-NoComercial-CompartirIgual 3.0 Costa Rica. Para más información envíe un mensaje a 
Revista Estudios, (39), 2019.

Diciembre 2019-Mayo 2020

ISSN 1659-3316

Urbina Gaitán Chester

ruptura con la dominación de una potencia que menosprecia la composición étnica y la fe religiosa tradicional de los nicaragüenses.

${ }^{1} \mathrm{El}$ autor agradece los comentarios y sugerencias a una versión preliminar de este texto al Dr. Arturo Taracena Arriola y al Dr. Michel Gobat.

\section{Referencias}

Acuña Ortega, Víctor Hugo. (2018). La formación del Estado en Nicaragua y Costa Rica en perspectiva comparada: siglos XIX-XX. Recuperado de https://revistas.ucr.ac.cr/index.php/anuario/article/view/34583/pdf

Ayala Mora, Enrique, (Dir.). Historia general de América Latina, VII. Los proyectos nacionales latinoamericanos: sus instrumentos y articulación, 1870-1930. París/Madrid: Unesco/Trotta.

Bagú, Sergio. (1975). "Tres oligarquías, tres nacionalismos”. Cuadernos Políticos. Núm. 3.

Bertoni, Lilia. (1992). "Construir la nacionalidad: Héroes, estatuas y fiestas patrias, 1887-1891". Boletín del Instituto de Historia Argentina y Americana Dr. E. Ravignani. Núm. 5. Buenos Aires: FCE.

Blázquez, Gustavo. (2000). "El Juramento, perdón... la promesa a la Bandera de los Argentinos. Actos escolares y violencia sémica". VI Congreso Argentino de Antropología Social, Mar del Plata.

Collado H., María del Carmen. (1988). "Liberales y conservadores de Nicaragua ¿falsos estereotipos?" Secuencia. Núm.11.

Cumberland, W.W. (1978). Nicaragua: investigación económica y financiera. Managua: Colección Cultural Banco de América.

de León Olivares, Isabel Dolores. (2015). Resistencias discursivas de intelectuales de República Dominicana durante la ocupación estadounidense de 19161924: nacionalismo, antiimperialismo e hispanismo. Recuperado de http://www.scielo.org.mx/scielo.php?script=sci arttext\&pid=S1870-

\section{X2015000200004}

\section{(C) $(\Theta \odot$}

La Revista Estudios es editada por la Universidad de Costa Rica y se distribuye bajo una Licencia Creative Commons Atribución-NoComercial-CompartirIgual 3.0 Costa Rica. Para más información envíe un mensaje a revistaestudios.eeg@ucr.ac.cr. 
Delgado, José Salomón. (1974). “Unidades de producción más importantes durante el período de los 30 años conservadores (hacienda tradicional y la mano de obra)". Anuario de Estudios Centroamericanos. Núm.1. San José: Universidad de Costa Rica.

Diario de Nicaragua, 18 de septiembre de 1895.

Díaz Arias, David. (2005a). La invención de las naciones en Centroamérica. Recuperado de http://afehc-historiacentroamericana.org/index.php?action=fi aff\&id=367

Díaz Arias, David. (2005b). Construcción de un Estado moderno: Política, Estado e Identidad Nacional en Costa Rica, 1821-1914. San José: Editorial de la Universidad de Costa Rica.

Díaz Arias, David. (2007). La fiesta de la independencia en Costa Rica, 18211921. San José: Editorial de la Universidad de Costa Rica.

Díaz Arias, David. (2007). "Entre la guerra de castas y la ladinización. La imagen del indígena en la Centroamérica liberal, 1870-1944". Revista de Estudios Sociales. Universidad de los Andes, Colombia. Num.26.

Díaz Arias, David. (2011). "Pequeños patriotas y ciudadanos. Infancia, nación y conmemoración de la independencia en Costa Rica, 1899-1932". Araucaria. Vol.13. Núm. 25.

Donoso Romo, Andrés. (2010). "La nación como protagonista de la educación en América Latina 1870-1930". Revista Historia de la Educación Latinoamericana. Universidad Pedagógica y Tecnológica de Colombia. Núm. 14.

El Comercio, 17 de setiembre de 1903.

El Comercio, 14 de setiembre de 1906.

Escobar, Esteban. (1968). "El libro del mes: Biografía del General Pedro Joaquín Chamorro". Revista Conservadora del Pensamiento Centroamericano. Vol.92. Núm.19.

\section{(-) 100}

La Revista Estudios es editada por la Universidad de Costa Rica y se distribuye bajo una Licencia Creative Commons Atribución-NoComercial-CompartirIgual 3.0 Costa Rica. Para más información envíe un mensaje a 
Esgueva Gómez, Antonio. (1999). Conflictos y paz en la Historia de Nicaragua. Managua: Instituto de Historia de Nicaragua y Centroamérica-Universidad Centroamericana.

Fernández Ampié, Guillermo. (2008). Variaciones de la idea de nación y patria en los textos escolares de Historia de Nicaragua. 1871-1930: El arduo camino en la construcción del sentimiento de nacionalidad nicaragüense. Recuperado de https://revistas.ucr.ac.cr/index.php/dialogos/article/view/31212

Gaceta de Nicaragua, 22 de setiembre de 1866.

Gaceta de Nicaragua, 19 de setiembre de 1868.

Gaceta de Nicaragua, 19 de setiembre de 1874.

Gaceta de Nicaragua, 18 de setiembre de 1875.

Gaceta de Nicaragua, 18 de setiembre de 1877.

Gaceta Oficial, Martes 17 de setiembre de 1878.

Gaceta Oficial, 18 de setiembre de 1880.

Gaceta Oficial, 20 de setiembre de 1884.

Gaceta Oficial, 19 de setiembre de 1885.

Gaceta Oficial, 18 de setiembre de 1886.

Gaceta Oficial, 17 de setiembre de 1887.

Gaceta Oficial, 19 de setiembre de 1888.

Gaceta Oficial, 18 de setiembre de 1889.

Gaceta Oficial, 17 de setiembre de 1890.

Gaceta Oficial, 17 de setiembre de 1892.

Gaceta Oficial, 17 de setiembre de 1893.

Gaceta Oficial, 17 de setiembre de 1897.

Gellner, Ernest. (1983). Nations and Nationalism. Ithaca: Cornell University Press.

Gobat, Michel. (2005). Confronting the American dream: Nicaragua under U.S. imperial rule. Durham/Londres: Duke University Press.

\section{(c) (i) (2)}

La Revista Estudios es editada por la Universidad de Costa Rica y se distribuye bajo una Licencia Creative Commons Atribución-NoComercial-CompartirIgual 3.0 Costa Rica. Para más información envíe un mensaje a 
Gould, Jeffrey L. (1995). "Y el buitre respondió: "aquí no hay indios"— la cuestión indígena en Nicaragua occidental, 1920-1964”. Mesoamérica. Vol. 16. Núm. 30, Antigua: CIRMA.

Gould, Jeffrey L. (1997). El mito de "la Nicaragua mestiza" y la resistencia indígena, 1880-1980. San José: Editorial de la Universidad de Costa Rica.

Greenfeld, Liah. (1992). Nationalism. Five Roads to Modernity. Cambridge (Mass.): Harward University Press.

Guibernau, Montserrat. (1999). Nations without States. Cambridge: Polity.

Herring, Hubert. (1962). A History of Latin America From the Beginnings to the Present. New York: Alfred A. Knopf.

Hobsbawm, Eric. (1991). Naciones y nacionalismos desde 1780. Barcelona: Crítica.

Hobsbawm, Eric y Ranger, Terence, (Eds.). (2002). La invención de la tradición. Barcelona: Crítica.

Kinloch, Frances. (1999). Nicaragua: Identidad y Cultura Política (1821-1858). Managua: Banco Central de Nicaragua.

La Gaceta, 30 de diciembre de 1918.

La Gaceta, 9 de agosto de 1922.

La Tribuna, 14 de setiembre de 1918.

La Tribuna, 13 de setiembre de 1925.

La Tribuna, 14 de setiembre de 1928.

Lanuza Matamoros, Aberto. (1976). Estructuras socioeconómicas, poder y estado en Nicaragua, de 1821 a 1875. Tesis de Grado. Universidad de Costa Rica. López Bernal, Carlos Gregorio. (2005). La patria en el corazón: Las celebraciones de la independencia en El Salvador (1824-1916). Recuperado de http://afehc-historia-centroamericana.org/index.php?action=fi aff\&id=363

Malek Anoar, Abdel. (1975). La dialéctica social. México: Siglo XXI.

Mc Laren, Peter. (1995). La Escuela como un perfomance ritual. México: Siglo XXI.

\section{(c) (i) (2)}

La Revista Estudios es editada por la Universidad de Costa Rica y se distribuye bajo una Licencia Creative Commons Atribución-NoComercial-CompartirIgual 3.0 Costa Rica. Para más información envíe un mensaje a revistaestudios.eeg@ucr.ac.cr. 
Memorias del IV Simposio Panamericano de Historia. (2001). México, IPGH.

Merlet, Michel. (1990). "El siglo diecinueve en Nicaragua. Auge y derrota de la vía campesina (1821-1934)". Ponencia presentada en el Simposio Las sociedades agrarias centroamericanas. Escuela de Historia de la Universidad Nacional de Costa Rica.

Miscevic, Nenad, (Ed.). (2000). Nationalism and ethnic conflict: philosophical perspectives. La Salle III: Open Court.

Molina Jiménez, Iván y Fumero Vargas, Patricia. (1997). La sonora libertad del viento: sociedad y cultura en Costa Rica y Nicaragua (1821-1914). México, IPGH.

Murillo Ferrol, Francisco. (1972). Estudios de Sociología Política. Madrid: Tecnos.

Ommen, T.K. (1997). Citizenship, Nationality and Ethnicity. Cambridge: Polity.

Rodríguez Rosales, Isolda. (1998). La educación durante el liberalismo, Nicaragua: 1893-1909. Managua: HISPAMER.

Rodríguez Rosales, Isolda. (2005). Historia de la educación en Nicaragua:

Restauración Conservadora (1910-1930). Managua: Hispamer.

Sieyes, E.J. (1989). ¿Qué es el Tercer Estado? Madrid: Alianza.

Smith, Anthony. (1997). La identidad nacional. Madrid: Trama.

Teplitz, Benjamin. (1974). "The Political and Economic Foundations of Modernization in Nicaragua. The Administration of Jose Santos Zelaya, 1893-1909". Tesis doctoral. Howard University, Ann Arbor, University Microfilms International.

Urbina Gaitán, Chester. (2015a). La celebración de la independencia en Nicaragua en el siglo XIX. Recuperado de http://www.red-redial.net/bicentenariobibliografia-america-pais-nicaragua.html

Urbina Gaitán, Chester. (2015b). Diversiones públicas y Estado en Nicaragua 1877-1936. Recuperado de https://revistas.ucr.ac.cr/index.php/anuario/article/view/21844

\section{(c) (i) (2)}

La Revista Estudios es editada por la Universidad de Costa Rica y se distribuye bajo una Licencia Creative Commons Atribución-NoComercial-CompartirIgual 3.0 Costa Rica. Para más información envíe un mensaje a revistaestudios.eeg@ucr.ac.cr. 
Revista Estudios, (39), 2019.

Diciembre 2019-Mayo 2020

ISSN 1659-3316

Urbina Gaitán Chester

Urbina Gaitán, Chester. (2018). Celebraciones nacionales, intelectuales y prensa en Nicaragua (1903-1928). Recuperado de http://www.cialc.unam.mx/cuadamer/textos/ca166-101.pdf

Vargas González, Hugo. (2008). La República Conservadora: ¿Un mito en la historiografía nicaragüense? Recuperado de https://revistas.ucr.ac.cr/index.php/dialogos/article/view/6141

Wolfe, Justin. (2004). "Those that Live by the Work of Their Hands: Labour, Ethnicity and Nation-State Formation in Nicaragua, 1850-1900." Journal of Latin American Studies. Vol. 36. Núm. 1.

Wolfe, Justin. (2007). The Everyday Nation-State: Community and Ethnicity in Nineteenth-Century Nicaragua. Lincoln: University of Nebraska Press.

Wolfe, Justin. (2009). Contra la corriente nacional: ideologías pos independistas de la formación del estado e identidades políticas locales, 1798-1858. Recuperado de http://www.afehc-historiacentroamericana.org/index_action_fi_aff_id_2330.html

La Revista Estudios es editada por la Universidad de Costa Rica y se distribuye bajo una Licencia Creative Commons Atribución-NoComercial-CompartirIgual 3.0 Costa Rica. Para más información envíe un mensaje a revistaestudios.eeg@ucr.ac.cr. 